\title{
Comparison of second-derivative spectrophotometry and HPLC for determination of amygdalin in wild apricot kernels
}

\author{
Xingjun Miao, Zhong Zhao*, Hailan Zhu, Ming Li, Qingxia Zhao \\ Key Laboratory of Environment and Ecology in Western China of Ministry of Education, College of Forestry, \\ Northwest A \& F University, 712100, China \\ *Corresponding author, e-mail: zhaozh@nwsuaf.edu.cn
}

Received 8 Jan 2013

Accepted 10 Apr 2013

\begin{abstract}
Amygdalin is a cyanogenic glucoside found in apricot kernels. To facilitate the exploitation and use of wild apricot resources, it is necessary to be able to rapidly and efficiently determine the amygdalin levels within their kernels. To do so, this paper compares two methods, one based on second-derivative UV spectrophotometry and the other on highperformance reversed-phase liquid chromatography (HPLC). The second-derivative spectrophotometry method effectively eliminates background noise and is straightforward to perform while retaining the accuracy of the HPLC method. It is likely to be a useful tool for the large-scale determination of amygdalin concentrations in wild apricot kernels and press cake.
\end{abstract}

KEYWORDS: cyanogenic glucoside, absorption spectra, chemical analysis, press cake

\section{INTRODUCTION}

The dry mature seeds of Armeniaca sibirica L., Armeniaca mandshurica (Maxim.), and Armeniaca vulgaris Lam., which are wild apricot kernels, are usually bitter due to the presence of amygdalin. Amygdalin, the cyanogenic diglucoside D-mandelonitrile- $\beta$-Dgentiobioside, is usually present in apricot kernels, bitter almonds, and the seeds of other members of the genus Prunus ${ }^{1,2}$. It is potentially dangerous because it can undergo hydrolysis to produce hydrogen cyanide $(\mathrm{HCN})$. The ingestion of apricot kernels can thus cause cyanide poisoning ${ }^{3}$.

Various techniques have been used to determine the amygdalin contents of different foods and industrial materials ${ }^{4}$. One of the first such methods developed was the acid hydrolysis method, which is applicable for all cyanogenic glucosides. However, to get accurate results using this method, one must heat the sample in an acidic solution and make measurements at multiple different reaction times in order to estimate the conditions at the start of the reaction by extrapolation. As a result, this method is difficult and less accurate and reproducible than the picrate method. More recently-developed alternatives include the resorcinol method $^{5}$ and direct analysis of the seed amygdalin content using high performance liquid chromatography (HPLC). This last method has been applied to the seeds of several apricot cultivars ${ }^{6,7}$. Gas chro- matograph/mass spectrometry (GC/MS) and Enzyme immunoassays have also been used for determining the cyanide content of apricot kernels ${ }^{8,9}$. However, most of the current instrument-based methods are very laborious and time-consuming. A newer more effective method is second-derivative spectrophotometry, which has previously been used to determine the amygdalin content of Prunus mume Puerarin and wild apricots ${ }^{10,11}$. In this work, we compare the performance of second-derivative spectrophotometry and HPLC in determining the amygdalin content of wild apricot kernels.

\section{MATERIALS AND METHODS}

All analyses were performed using methanol as the solvent. D-Amygdalin (D-mandelonitrile $\beta$-D-glucosido-6- $\beta$-D-glucoside) was purchased from Sigma Chemistry Co. Ltd., Germany.

Wild apricot seeds were purchased in Qingyang City, Gansu Province, China. The seeds were cracked open and the soft kernels were dried to constant weight in an air convection oven at $103 \pm 2{ }^{\circ} \mathrm{C}^{12}$. The dried kernels were then ground into power using a pestle and mortar and stored at $-20^{\circ} \mathrm{C}$ until analysis.

\section{The second-derivative spectrum method}

Absorption spectra were measured using a Shimadzu recording spectrophotometer, model UV-1700, over a scanning range of $250-275 \mathrm{~nm}$ with a high scanning 
speed and a derivative wavelength difference of $\Delta \lambda=$ $2 \mathrm{~nm}$. Amplitudes were recorded between $266 \mathrm{~nm}$ and $268 \mathrm{~nm}^{11,13}$.

A $0.6 \mathrm{mg} / \mathrm{ml}$ amygdalin stock solution in methanol was prepared for use as a standard. A serial dilution of this stock solution in methanol was then prepared to give standard solutions at concentrations of $0,0.10,0.15,0.20,0.30$, and $0.50 \mathrm{mg} / \mathrm{ml}$.

\section{The HPLC method}

About $1 \mathrm{ml}$ of filtered apricot kernel extract was filtered through a $0.22 \mu \mathrm{m}$ micro-filter. The amygdalin content of the solution was determined using a Hitachi Technologies L2000 series liquid chromatograph coupled to a Hitachi L2455 diode array detector. Quantification was performed using a $\mathrm{C} 18$ reversed phase column $(250 \mathrm{~mm} \times 4.6 \mathrm{~mm}, 5.0 \mu \mathrm{m})$ at $25^{\circ} \mathrm{C}$ using a Hitachi L-2300 column oven. Chromatography was performed using a flow rate of $0.8 \mathrm{ml} / \mathrm{min}$, a 15:85 acetonitrile:water mixture as the eluent, $20 \mu \mathrm{l}$ of sample, and with detection under UV at $214 \mathrm{~nm}$ using Hitachi L2455 DAD detector. All analyses were performed in triplicate. Standard curves for the HPLC and spectrophotometric methods were prepared by analysing the stock solution serial dilution using the protocols described above.

\section{Statistical analysis}

The reproducibility and stability of the second-derivative spectrophotometry results were analysed for statistical significance using ANOVA (SPSS 16.0). Mean separation was evaluated using Duncan's multiple range test. Differences between the results obtained with HPLC and second-derivative spectrophotometry were analysed using the $t$-test (SPSS 16.0). Differences were considered statistically significant when $p<0.05$.

\section{RESULTS}

\section{Reproducibility and stability of the second- derivative spectrophotometry results}

The second-derivative spectrophotometry calibration curves were linear. Regression analysis yielded the following relationship between concentration $(y)$ and amplitude $(x): y=5.823 x+0.0019\left(r^{2}=0.9987\right)$. The reproducibility of the analyses was tested for six different sample standing times using five different samples in each case. The intra-day coefficient of variation ranged from $2.4 \%$ to $3.5 \%$. The highest amygdalin concentrations were observed for samples left to stand for at least $8 \mathrm{~h}$ (Table 1), and the measured amygdalin concentration decreased significantly in
Table 1 Reproducibility of measured amygdalin levels from samples $(n=15)$.

\begin{tabular}{lcc}
\hline $\begin{array}{l}\text { Standing } \\
\text { time }(\mathrm{h})\end{array}$ & $\begin{array}{c}\text { Assay value } \\
(\text { dry base, \%) }\end{array}$ & $\begin{array}{c}\text { Coefficient of } \\
\text { variation }(\%)\end{array}$ \\
\hline 0 & $5.01 \pm 0.18^{\mathrm{d}^{*}}$ & 3.5 \\
2 & $5.18 \pm 0.16^{\mathrm{c}}$ & 3.1 \\
4 & $5.14 \pm 0.14^{\mathrm{c}}$ & 2.8 \\
6 & $5.25 \pm 0.17^{\mathrm{bc}}$ & 3.2 \\
8 & $5.33 \pm 0.16^{\mathrm{ab}}$ & 3.0 \\
10 & $5.38 \pm 0.13^{\mathrm{a}}$ & 2.4 \\
\hline
\end{tabular}

* Entries in this column that are followed by the same letter do not differ significantly from one-another $(p<$ $0.05)$.

samples that had been stored for 5 days or more $(p<$ 0.05, Table 2).

\section{Extraction recoveries}

The ratio of the assay value to the spiked amount for standard was calculated as $(A-B) / C$, where $A$ is the amount detected, $B$ is the amount of sample without standard, and $C$ is the spiked amount of the standard. The recovery of amygdalin was $99.08 \%$ (Table 3 ).

\section{Differences between the results obtained using HPLC and second-derivative spectrophotometry}

The HPLC calibration curve was linear. Regression analysis yielded the following equation describing the relationship between peak area $(y)$ and concentration $(x): y=280225 x+1806.5\left(r^{2}=0.9991\right)$.

The paired-samples $t$-test showed that the amygdalin concentrations measured using second-derivative spectrophotometry were higher than those determined using HPLC $(p=0.000)$. However, the paired samples correlation for the two methods was 0.975 ( $p=0.000)$, indicating that their results are strongly correlated. Two samples were found to contain no amygdalin by both HPLC and second-derivative spectrophotometry.

\section{DISCUSSION}

HPLC is generally considered to be more practically convenient than either gas chromatography or capillary electrophoresis ${ }^{14}$. It has been used to analyse amygdalin levels in the flowers of Eriobotrya japon$i c a$, apricot kernels, almonds, and other species ${ }^{6,15,16}$.

Derivative spectrophotometry is a useful tool in chemical analysis because it can separate overlapping signals and eliminate background. This makes it possible to quantify analyses without initial separation or purification. It has therefore found applications in the pharmaceutical industry, clinical medicine, and 
Table 2 Stability of amygdalin in samples $(n=10)$.

\begin{tabular}{lccccc}
\hline Standing time (h) & 1-day & 2-day & 3-day & 4-day & 5-day \\
\hline 0 & $5.06 \pm 0.17^{\mathrm{a}^{*}}$ & $4.98 \pm 0.14^{\mathrm{ab}}$ & $4.97 \pm 0.14^{\mathrm{ab}}$ & $5.00 \pm 0.19^{\mathrm{a}}$ & $4.84 \pm 0.13^{\mathrm{b}}$ \\
2 & $5.28 \pm 0.08^{\mathrm{a}}$ & $5.12 \pm 0.16^{\mathrm{bc}}$ & $5.10 \pm 0.11^{\mathrm{bc}}$ & $5.18 \pm 0.13^{\mathrm{ab}}$ & $5.02 \pm 0.01^{\mathrm{c}}$ \\
4 & $5.20 \pm 0.12^{\mathrm{a}}$ & $5.14 \pm 0.17^{\mathrm{a}}$ & $5.10 \pm 0.14^{\mathrm{a}}$ & $5.12 \pm 0.16^{\mathrm{a}}$ & $4.97 \pm 0.11^{\mathrm{b}}$ \\
6 & $5.29 \pm 0.17^{\mathrm{a}}$ & $5.26 \pm 0.20^{\mathrm{a}}$ & $5.21 \pm 0.19^{\mathrm{ab}}$ & $5.29 \pm 0.20^{\mathrm{a}}$ & $5.08 \pm 0.18^{\mathrm{b}}$ \\
8 & $5.37 \pm 0.15^{\mathrm{a}}$ & $5.39 \pm 0.22^{\mathrm{a}}$ & $5.33 \pm 0.16^{\mathrm{ab}}$ & $5.36 \pm 0.12^{\mathrm{a}}$ & $5.20 \pm 0.17^{\mathrm{b}}$ \\
10 & $5.43 \pm 0.12^{\mathrm{a}}$ & $5.40 \pm 0.17^{\mathrm{ab}}$ & $5.37 \pm 0.06^{\mathrm{ab}}$ & $5.45 \pm 0.14^{\mathrm{a}}$ & $5.29 \pm 0.12^{\mathrm{b}}$ \\
\hline
\end{tabular}

* Entries between the columns that are followed by the same letter do not differ significantly.

Table 3 Testing the recovery of amygdalin $(n=5)$.

\begin{tabular}{lccc}
\hline $\begin{array}{l}\text { Sample } \\
\text { amount }(\mathrm{mg})\end{array}$ & $\begin{array}{c}\text { Spiked } \\
\text { amount }(\mathrm{mg})\end{array}$ & $\begin{array}{c}\text { Assay } \\
\text { value }(\mathrm{mg})\end{array}$ & $\begin{array}{c}\text { Recovery } \\
\text { rate }(\%)\end{array}$ \\
\hline $8.07 \pm 0.10$ & 0.98 & $9.04 \pm 0.10$ & 99.08 \\
\hline
\end{tabular}

Table 4 Differences in the results obtained with HPLC and second-derivative spectrophotometry $(n=16)$.

\begin{tabular}{lcc}
\hline $\begin{array}{l}\text { HPLC } \\
(\mathrm{mg} / \mathrm{ml})\end{array}$ & $\begin{array}{c}\text { Second-derivative spectrophotometry } \\
(\mathrm{mg} / \mathrm{ml})\end{array}$ \\
\hline $0.18 \pm 0.09$ & $0.21 \pm 0.10$ \\
\hline \hline Paired difference & $t$-value & Sig. (2-tailed) \\
\hline $0.028 \pm 0.023$ & 4.918 & 0.000 \\
\hline
\end{tabular}

biochemistry, among other fields ${ }^{10}$. Because it is simple to perform, can be done rapidly, and gives accurate results in the determination of amygdalin, it may be an attractive tool for routine use in quality control laboratories that can be used by relatively unskilled workers. The methanol used in this work is a volatile and toxic solvent. To minimize the amount of methanol used, we tested an alternative extraction process using a Soxhlet apparatus ${ }^{6}$. While this reduced the volume of methanol used in the extraction, it increased the amount of time required for sample preparation, and so the ultrasonic method was preferred. While amygdalin is readily dissolved in methanol, it could also potentially be extracted into water containing $0.1 \%$ citric acid under reflux, which may be a more attractive option ${ }^{14}$. It should be noted that there are both bitter and sweet wild apricot kernels. We found that sweet kernels contained no amygdalin, in keeping with a report on sweet apricots cultivars form Mallorca (Spain) ${ }^{17}$. The amygdalin concentrations measured using second-derivative spectrophotometry were generally somewhat higher than those determined using HPLC. However, for samples containing between $0.217 \mathrm{mg} / \mathrm{ml}$ and $0.284 \mathrm{mg} / \mathrm{ml}$, there was a strong correlation between the concentrations measured using the two methods, making it possible to estimate the HPLC value from the spectrophotometric data.

Second-derivative spectrophotometry thus appears to be a powerful and generally useful tool for measuring the amygdalin contents of wild apricot kernels. Moreover, it should also be suitable for determining the amygdalin content of the press cake. To avoid contaminating the press cake with toxic methanol, one could initially extract amygdalin using edible ethanol, then dry the resulting extract in a vacuum oven and re-dissolve it in methanol to obtain a sample suitable for analysis by second-derivative spectrophotometry.

The second-derivative spectrophotometry method is likely to be a useful and attractive tool for routine use in quality control laboratories for the large-scale determination of amygdalin concentrations in wild apricot kernels and press cake.

Acknowledgements: We are thankful to Hang Yu, Master Ling Li, Master Wenjun Pu and Master Yanjun Zhang for their generous technical assistance with HPLC analyses. We thank Dr Meili Wang and Dr Jingjing Zhou for their help in writing this manuscript. Our studies were supported by a grant from the research and development of deep processing technology of kernel-apricot, PR China (Special Research Programme for Public-welfare Forestry of the Chinese State Forestry Administration No. 200904020). The work was completed in the Key Laboratory of Environment and Ecology in Western China, Ministry of Education.

\section{REFERENCES}

1. Barceloux DG (2009) Cyanogenic foods (cassava, fruit kernels, and cycad seeds). Dis Mon 55, 336-52.

2. Zhao Y (2012) Amygdalin content in four stone fruit species at different developmental stages. Sci Asia 38, $218-22$.

3. Suchard JR, Wallace KL, Gerkin RD (1998) Acute cyanide toxicity caused by apricot kernel ingestion. Ann Emerg Med 32, 742-4. 
4. Rezaul Haque M, Howard Bradbury J (2002) Total cyanide determination of plants and foods using the picrate and acid hydrolysis methods. Food Chem 77, 107-14.

5. Drochioiu G, Arsene C, Murariu M, Oniscu C (2008) Analysis of cyanogens with resorcinol and picrate. Food Chem Toxicol 46, 3540-5.

6. Gómez E, Burgos L, Soriano C, Marín J (1998) Amygdalin content in the seeds of several apricot cultivars. J Sci Food Agr 77, 184-6.

7. Yildirim FA, Askin MA (2010) Variability of amygdalin content in seeds of sweet and bitter apricot cultivars in Turkey. Afr J Biotechnol 9, 6522-4.

8. Chassagne D, Crouzet JC, Bayonove CL, Baumes RL (1996) Identification and quantification of passion fruit cyanogenic glycosides. J Agr Food Chem 44, 3817-20.

9. Cho A-Y, Yi KS, Rhim J-H, Kim K-I, Park J-Y, Keum E-H, Chung J, Oh S (2006) Detection of abnormally high amygdalin content in food by an enzyme immunoassay. Mol Cell 21, 308-13.

10. Karpińska J (2004) Derivative spectrophotometryrecent applications and directions of developments. Talanta 64, 801-22.

11. Yali W, Jianpei L (2010) Determination of the amygdalin content of Fuctus mume Puerarin by second-class derivative spectrum. Chin J Ethnomed Ethnopharm 1, 31-2 [in Chinese].

12. Kashaninejad M, Mortazavi A, Safekordi A, Tabil LG (2006) Some physical properties of Pistachio (Pistacia vera $\mathrm{L}$.) nut and its kernel. J Food Eng 72, 30-8.

13. Wu D, Wang J-Z, Zhao Y-X, Wang H-Q (2006) The comparison between different analysis methods for mygdalin. Sci Tech Food Ind 2, 184-6 [in Chinese].

14. Lv W-F, Ding M-Y, Zheng R (2005) Isolation and quantitation of amygdalin in apricot-kernel and Prunus tomentosa Thunb. by HPLC with solid-phase extraction. J Chromatogr Sci 43, 383-7.

15. London-Shafir I, Shafir S, Eisikowitch D (2003) Amygdalin in almond nectar and pollen-facts and possible roles. Plant Systemat Evol 238, 87-95.

16. Zhou C, Chen K, Sun C, Chen Q, Zhang W, Li X (2007) Determination of oleanolic acid, ursolic acid and amygdalin in the flower of Eriobotrya japonica Lindl. by HPLC. Biomed Chrom 21, 755-61.

17. Femenia A, Rossello C, Mulet A, Canellas J (1995) Chemical composition of bitter and sweet apricot kernels. J Agr Food Chem 43, 356-61. 